
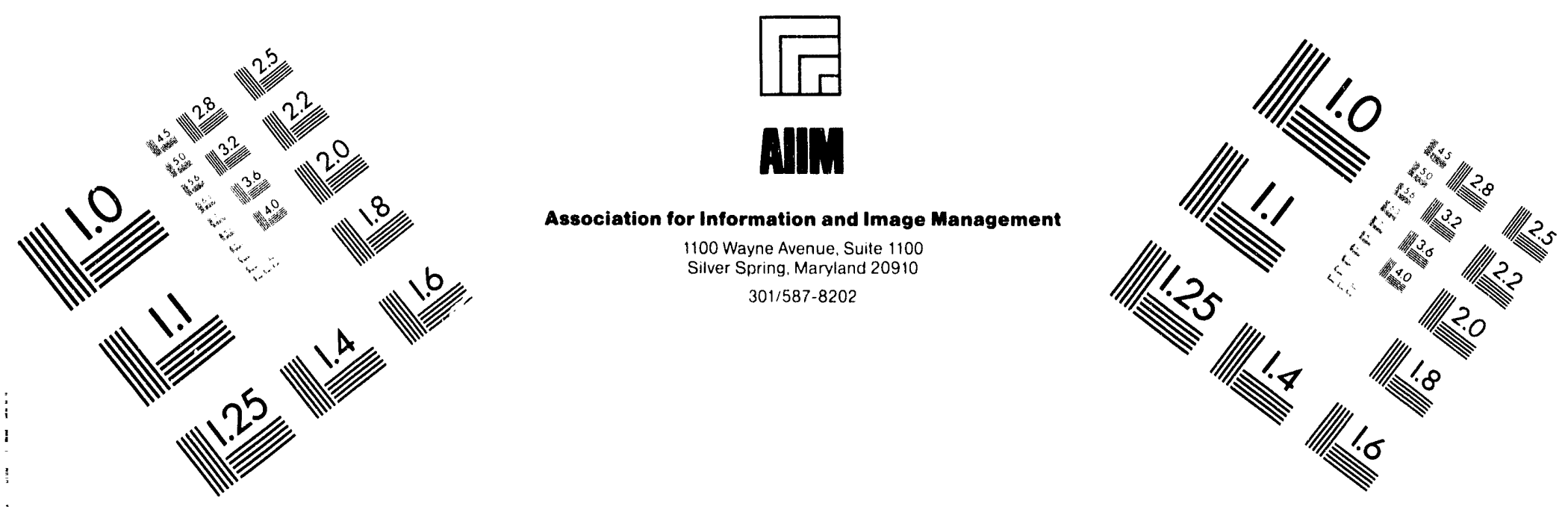

\title{
Centimeter
}

1 Inches
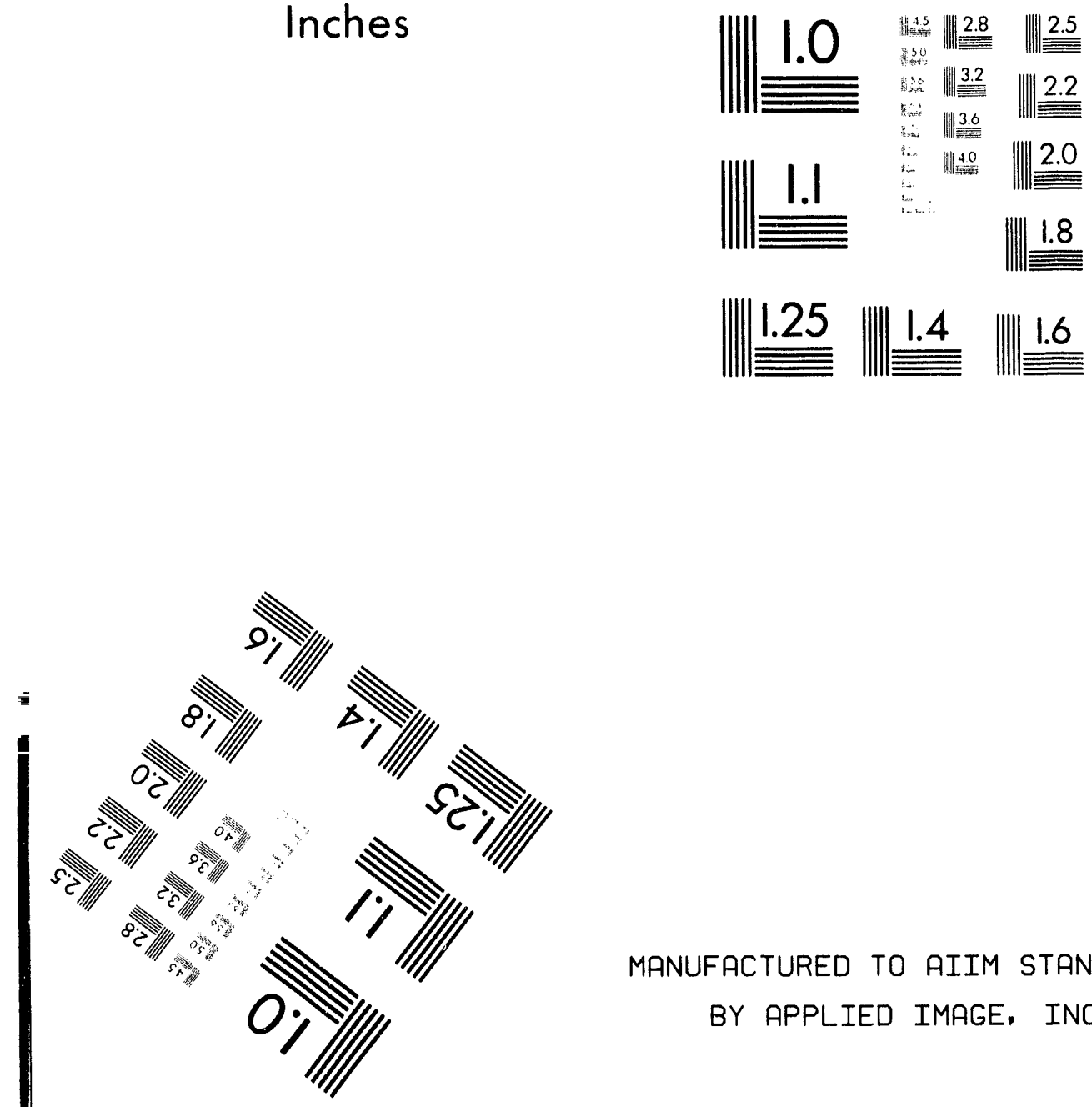

MANUFACTURED TO AIIM STANDARDS

BY APPLIED IMAGE, INC.

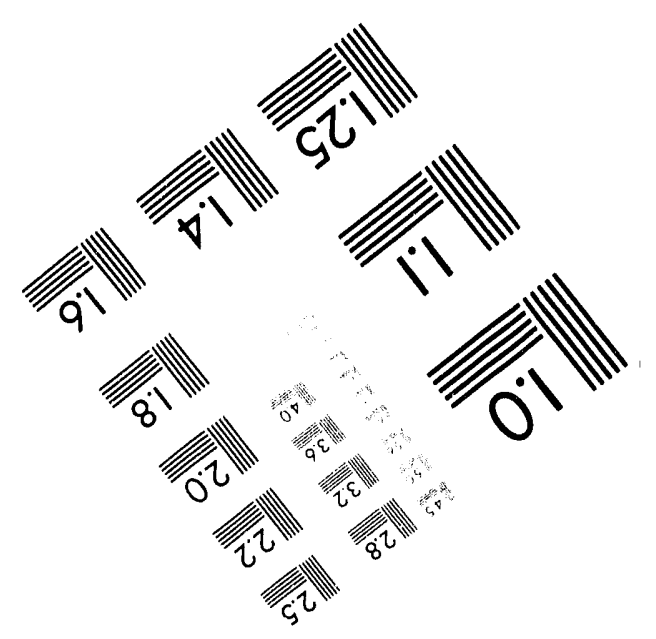



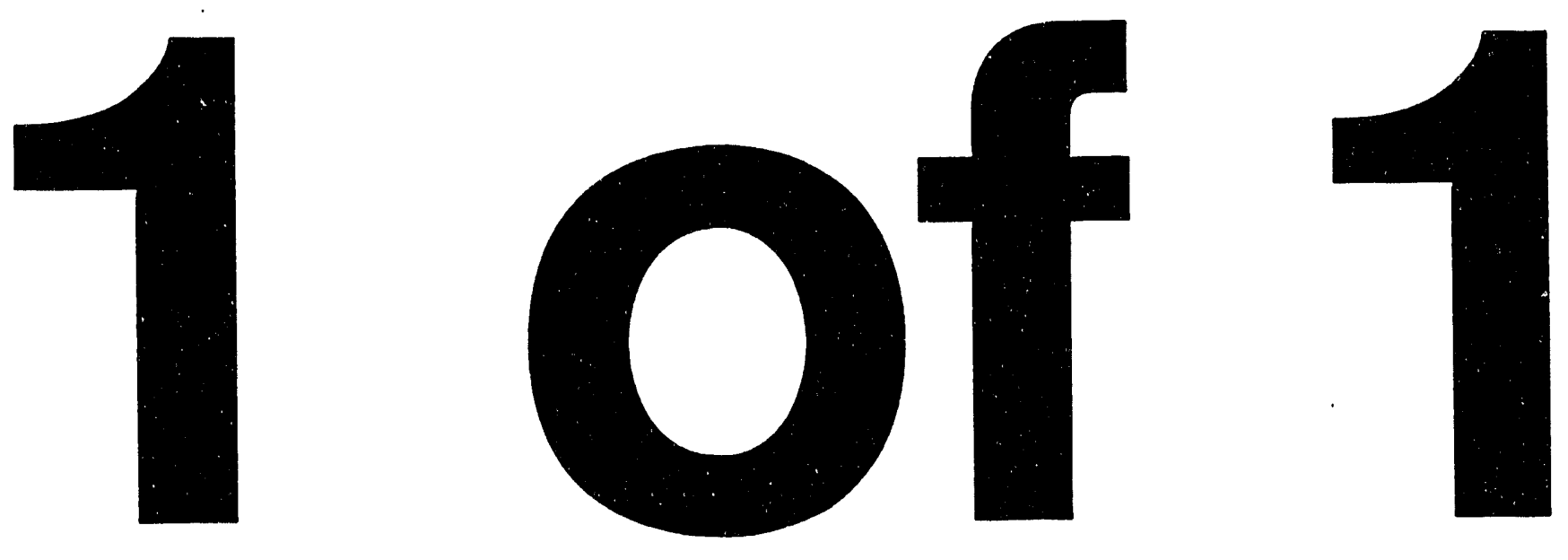
DOE/ER/13299-10

\section{DIOSMACYCLOALKANES AS MODELS FOR THE FORMATION OF HYDROCARBONS FROM SURFACE METHYLENES}

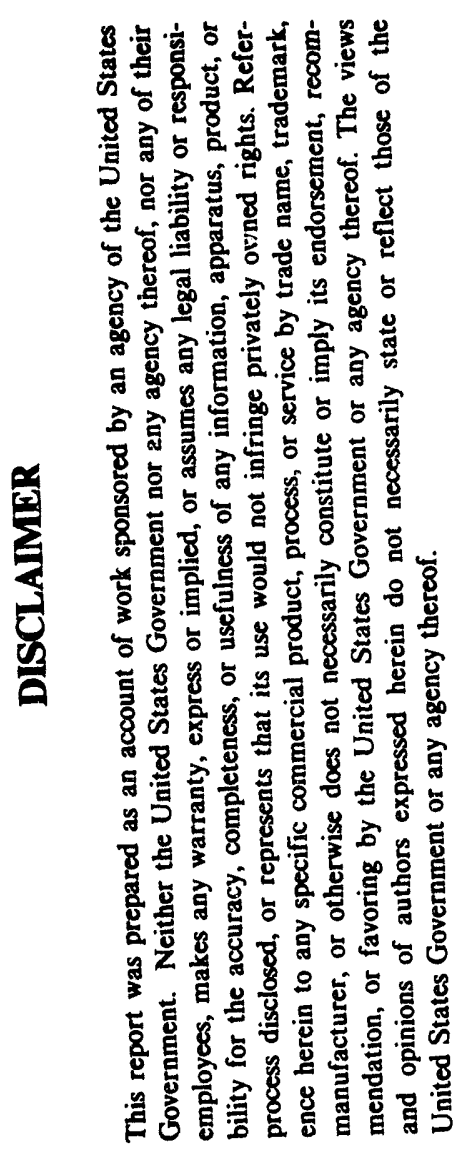

Final Report

Jack R. Norton

Principal Investigator

Colorado State University

Fort Collins, Colorado 80523

April 25, 1994

Prepared for

THE U.S. DEPARTMENT OF ENERGY AGREEMENT NO. DE-FG02-84ER13299

AGREEMENT NO. DE-FG02-84ER13299 


\begin{abstract}
Assignment of the vibrational modes of $\mathrm{Os}_{2}(\mathrm{CO})_{8}\left(\mathrm{CHCH}_{3}\right)$ and $\mathrm{Os}(\mathrm{CO})_{4}\left(\mathrm{C}_{2} \mathrm{H}_{4}\right)$ has given fingerprint vibrational spectra for the following species when chemisorbed on metal catalyst surfaces: ethylidene and ethylene bound in a metallacyclopropane mode.

The formation and fragmentation of diosmacyclobutanes have been shown to involve slippage of the outgoing olefin onto a single osmium, and associative exchange of the olefin from that site. The incorporation of vinylcyclopropane without rearrangement has confirmed the absence of a diradical intermediate. The anomalous stability of the diosmacyclobutane derived from trans-2-butene has proven due to greater destabilization (by the substituent methyls) of the slipped intermediate than of the ground state.

Reaction of an osmacyclobutane with 1,3- or 1,2-dienes (allenes) gives 1,2 rather than 1,4 addition to the diosmium unit. Treatment of $\mathrm{Os}(\mathrm{CO})_{4}\left(\mathrm{C}_{2} \mathrm{H}_{4}\right)$ with triflic acid results in the formation of Os $(\mathrm{CO})_{4}\left(\mathrm{C}_{2} \mathrm{H}_{5}\right)$ OTf.

We have found that the reaction of an aryl iodine(III) reagent with propargyl stannanes or silanes results in o-iodo propargyl arenes.
\end{abstract}




\section{Final Report \\ Department of Energy (Grant \#FG02-84ER13299) \\ Iack R. Norton, Principal Investigator}

[an updated version of the progress report

submitted with our renewal application]

\section{A. Vibrational Models for Surface Species}

\section{Publications:}

(a) "Assignments of the Infrared and Raman Spectra of the $\mathrm{Os}_{2}\left(\mu_{2}-\mathrm{CHCH}_{3}\right)$ Group of $\left[\left(\mu_{2}-\mathrm{CHCH}_{3}\right) \mathrm{Os}_{2}(\mathrm{CO})_{8}\right]$ and of their $\mathbf{d}^{\mathbf{1}}$ and $\mathbf{d}^{\mathbf{4}}$ Isotopologues as Models for the Spectrum of such Ethylidene Groups on Metal Surfaces", C. E. Anson, N. Sheppard*, D. B. Powell, J. R. Norton, W. Fischer, R. L. Keiter, B. F. G. Johnson, J. Lewis, A. K. Bhattacharrya, S. A. R. Knox, and M. L. Turner, J. Am. Chem. Soc. 1994, 116, 3058-62. [reprints have not yet arrived]

(b) " $\left[\left(\eta^{2}-\mathrm{C}_{2} \mathrm{H}_{4}\right) \mathrm{Os}(\mathrm{CO})_{4}\right]$ as a Vibrational Model for Type I' Ethene Chemisorbed as a Metallacyclopropane on Metal Surfaces", C. E. Anson, N. Sheppard*, D. B. Powell, B. R. Bender, and J. R. Norton, J. Chem. Soc., Faraday Trans. 1994, in press.

Goals: vibrational "fingerprints" of $\mathrm{CH}_{3} \mathrm{CH}$ and $\mathrm{C}_{2} \mathrm{H}_{4}$ so that they can be identified on metal catalyst surfaces

We have developed the following method for the preparation of $\mathrm{CH}_{3} \mathrm{CD}(\mathrm{OTf})_{2}$ and $\mathrm{CD}_{3} \mathrm{CD}(\mathrm{OTf})_{2}$, and have used these labelled geminal ditriflates for the preparation of $\mathrm{Os}_{2}(\mathrm{CO})_{8}\left(\mu-\mathrm{CDCH}_{3}\right)$ and $\mathrm{Os}_{2}(\mathrm{CO})_{8}\left(\mu-\mathrm{CDCD}_{3}\right)$. 


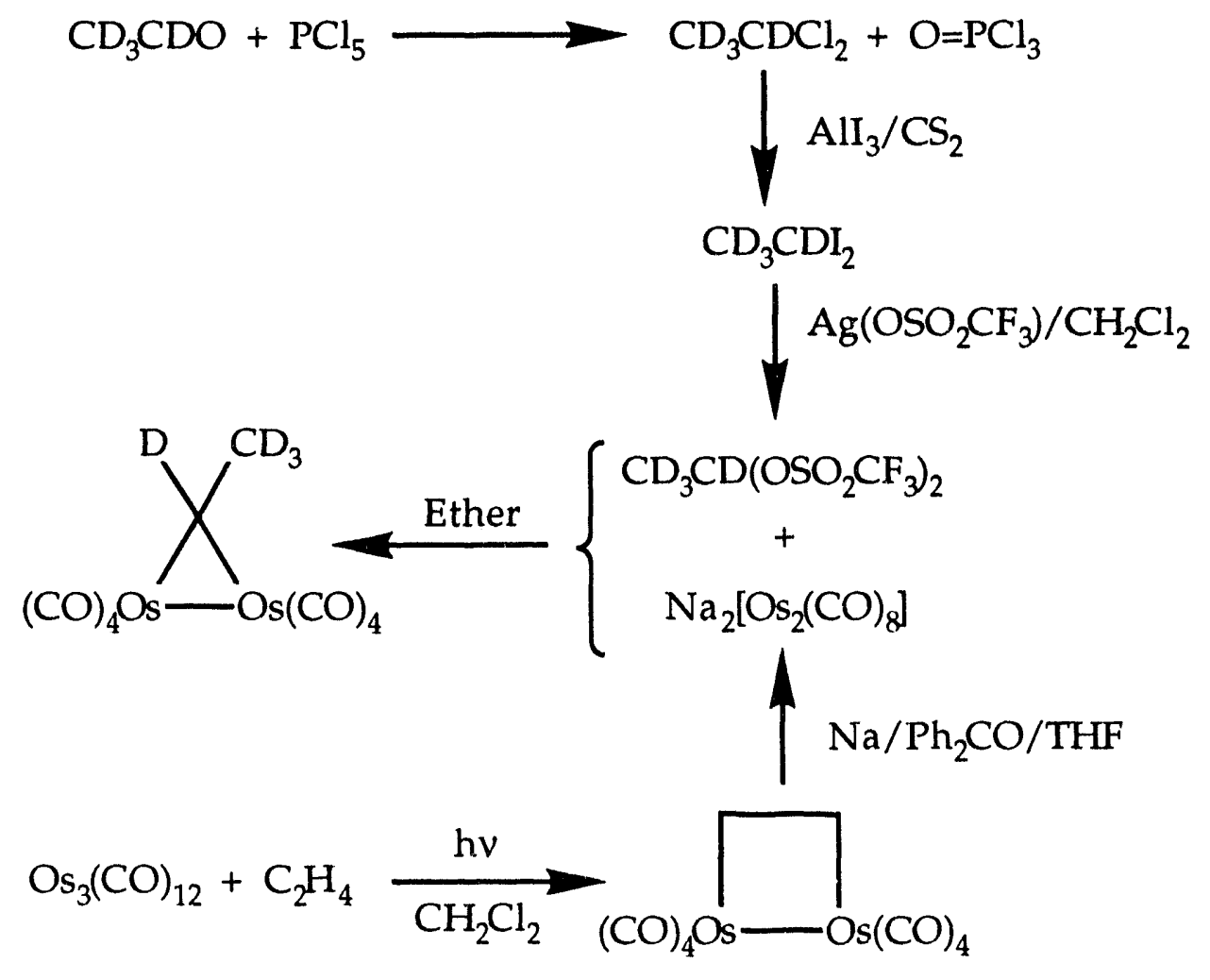

In collaboration with Anson and Sheppard we have obtained lowtemperature infrared and Raman spectra of these labelled diosmacyclopropanes and used them to assign unequivocally the vibrational modes of the bridging ethylidene ligands.

Previously reported surface ethylidenes 1 a have turned out to be ethylidynes $\left(\mathrm{CH}_{3} \mathrm{C}\right) .1 \mathrm{~b}-\mathrm{d}$ The information in the Table should enable the identification of an ethylidene species on the surface of a catalyst. The two apparent examples shown arise from (1) the adsorption of ethylene onto $\mathrm{Pt}(111)$ with preadsorbed oxygen, $1 \mathrm{~d}$ and (2) hydrogenation of $\mathrm{CO}$ adsorbed on $\mathrm{Rh} / \mathrm{Al}_{2} \mathrm{O}_{3} .{ }^{2}$ 
Table The assigned fundamentals ( $\mathrm{cm}-1)$ for the ethylidene groups in several metal coordination compounds and for possible ethylidene species on metal surfaces

\begin{tabular}{|c|c|c|c|c|}
\hline \multicolumn{2}{|c|}{$\left(\mu_{2}-C D C D_{3}\right) \operatorname{ss}_{2}(C O)_{8}$} & \multirow[t]{2}{*}{$\left(\mu_{2}-\mathrm{CHCH}_{3}\right) \mathrm{Os}_{2}(\mathrm{CO})_{8}$} & \multirow[t]{2}{*}{$\mid \begin{array}{l}\mathrm{CO} / \mathrm{H}_{2} / \\
\mathrm{Rh} / \mathrm{Al}_{2} \mathrm{O}_{3}\end{array}$} & \multirow[t]{2}{*}{$\begin{array}{l}\mathrm{C}_{2} \mathrm{H}_{4} / \\
\mathrm{Pt}(111) / \mathrm{O}\end{array}$} \\
\hline & & & & \\
\hline 2207 & $\mathrm{vCH}_{3} / \mathrm{CD}_{3}$ as & 2950 & $2964(s, b)$ & $2980(\mathrm{~ms}, \mathrm{~b})$ \\
\hline 2187 & $\vee C H / C D$ & 2918 & $2916(s, b)$ & \\
\hline- & $v \mathrm{CH}_{3} / \mathrm{CD}_{3} s$ & 2847 & & \\
\hline 1123 & $8 \mathrm{CH}_{3} / \mathrm{CD}_{3}$ as & 1449 & 1463(ms) & $1460(s)$ \\
\hline 1037 & $\& \mathrm{CH}_{3} / \mathrm{CD}_{3} \mathrm{~s}$ & 1369 & $1378(\mathrm{~m})$ & 1380 (ms,vb) \\
\hline 1023 & $\delta \mathrm{CH} / \mathrm{CD}$ ip & 1302 & $1256(\mathrm{~m})$ & 1380 (ms,vb) \\
\hline 928 & $\mathrm{\rho CH}_{3} / \mathrm{CD}_{3}$ & 1053 & $1058(\mathrm{~m})$ & \\
\hline 757 & $\mathrm{vCC}$ & 989 & $940(\mathrm{mw})$ & $940(m)$ \\
\hline 434 & yOsCs & 448 & & 480 (vs) \\
\hline 286 & $\delta \operatorname{ccos} s$ & 312 & & $300(\mathrm{~m})$ \\
\hline 155 & vOsOs & 155 & & \\
\hline \multicolumn{5}{|c|}{ Q"modes } \\
\hline$(2207)$ & $v \mathrm{CH}_{3} / \mathrm{CD}_{3}$ as & $(2950)$ & & \\
\hline 1054 & $\delta \mathrm{CH}_{3} / \mathrm{CD}_{3}$ as & (1449) & & \\
\hline 845 & $\rho \mathrm{CH}_{3} / \mathrm{CD}_{3}$ & 1030 & & \\
\hline 689 & $\delta C H / C D$ oop & 945 & & \\
\hline 525 & vOsC as & 545 & 594 (ms) & \\
\hline ca 176 & $\delta C \operatorname{COs} 00 p$ & 196 & & \\
\hline
\end{tabular}


A complete vibrational assignment of the $\mathrm{Os}\left(\mathrm{C}_{2} \mathrm{H}_{4}\right)$ moiety in the complex $\left(\eta^{2}-\mathrm{C}_{2} \mathrm{H}_{4}\right) \mathrm{Os}(\mathrm{CO})_{4}$ and its $\left({ }^{13} \mathrm{C}_{2} \mathrm{H}_{4}\right)$ and $\left(\mathrm{C}_{2} \mathrm{D}_{4}\right)$ isotopologues has been carried out. Comparisons with vibrational data for thiirane (ethene sulfide) and other metalethene complexes suggest that the $\mathrm{Os}\left(\mathrm{C}_{2} \mathrm{H}_{4}\right)$ complex has a high degree of metallacyclopropane character, more so than the other complexes so far investigated by vibrational spectroscopy.

Comparison with vibrational spectra from ethene chemisorbed on metal single-crystal surfaces indicates that some of the "Type I' " electron energy loss spectra, such as those obtained from $\operatorname{Pd}(100)^{3}$ and $\operatorname{Rh}(100)^{4}$ surfaces, result from metallacyclopropane-type surface species.

B. "Alpha vs. Beta Hydrogen Elimination in the Formation of Propene from an Osmacyclobutane", W. Fischer, R.T. Hembre, D.R. Sidler, and J.R. Norton, Inorg. Chim. Acta, 1992, 198-200, 57.

Question to be Answered: does $\alpha$-elimination play a role in the fragmentation of metallacyclobutanes?

We have examined the fragmentation of the osmacyclobutane below in a gasphase flow system. We have found the only product to be propylene, with no evidence for the cyclopropane Lindner ${ }^{5}$ has reported. Control experiments have shown that the deuterium content and distribution of propylene remain unaffected after it is formed. Over half the propylene is formed by the expected $\beta$ elimination. However, the formation of a significant amount of $\mathrm{CH}_{3} \mathrm{CD}=\mathrm{CHD}$ shows that, contrary to the conventional wisdom, some $\alpha$ elimination is occurring.

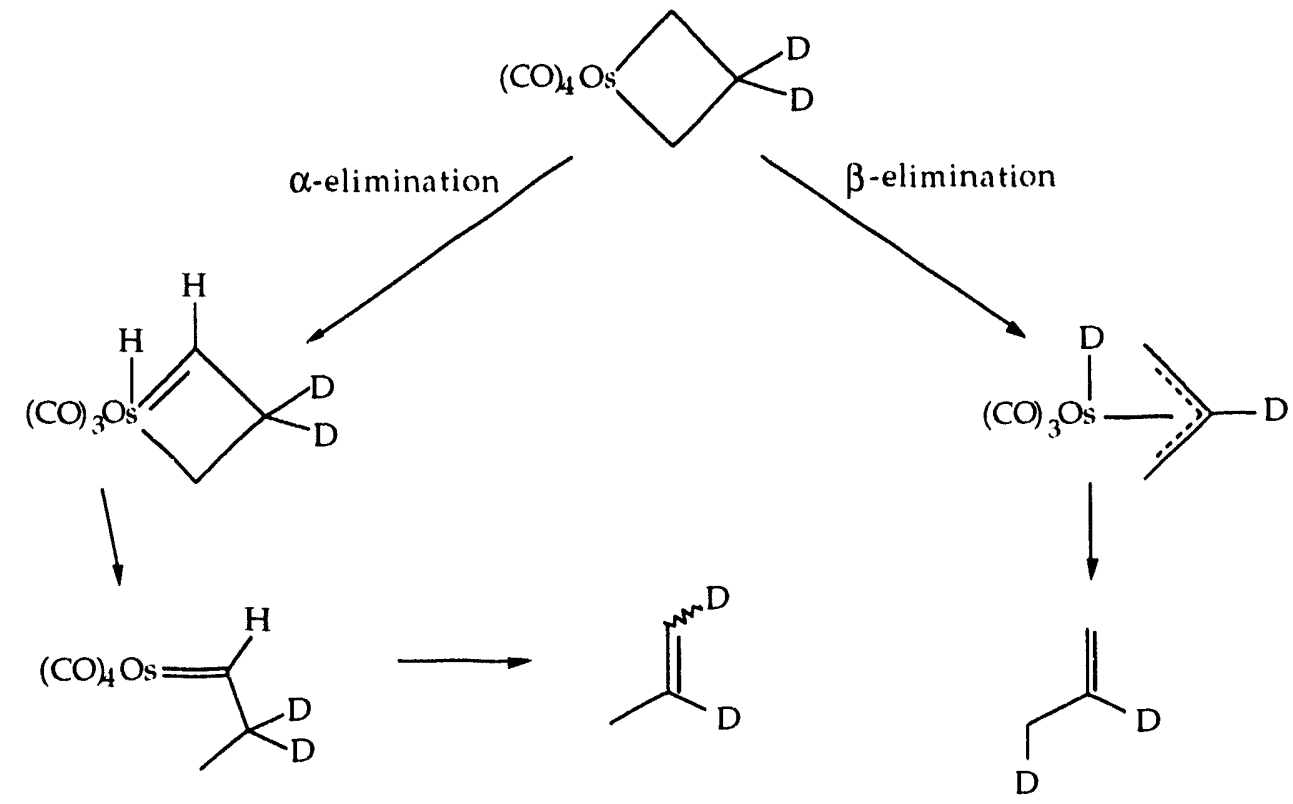




\section{Mechanism of the formation and fragmentation of diosmacyclobutanes.}

Publications that have appeared since 1990:

(a) "The Photochemistry of Dinuclear Osmium Carbonyl Complexes; Characterization of $\mathrm{Os}_{2}(\mathrm{CO})_{8}$ Using Matrix Isolation", A. Haynes, M. Poliakoff, J.J. Turner, B. Bender and J.R. Norton, J. Organomet. Chem. 1990, 383, 497.

(b) "A Single Crystal Neutron Diffraction Study of $\left(\mu-\eta^{1}, \eta^{1}-\mathrm{C}_{2} \mathrm{H}_{4}\right) \mathrm{Os}_{2}(\mathrm{CO})_{8}$, A Model for One Type of Chemisorbed Ethylene", O.P Anderson, B.R. Bender, J.R. Norton*, A.C. Larson*, and P.J. Vergamini, Organometallics 1991, 10, 3145.

(c) "Retention of Stereochemistry in the Formation and Fragmentation of Diosmacyclobutanes, and Other Evidence Against a Diradical Mechanism", R. T. Hembre, D. L. Ramage, Carl P. Scott, and J. R. Norton, Organometallics 1994, 13, in press.

Three additional publications are in draft form: They describe (1) the structures of $\left(\mu-\mathrm{C}_{2} \mathrm{H}_{4}\right) \mathrm{Os}_{2}(\mathrm{CO})_{8}$ and $\left(\eta^{2}-\mathrm{C}_{2} \mathrm{H}_{4}\right) \mathrm{Os}(\mathrm{CO})_{4}$ in a nematic phase solvent, (2) the kinetics and mechanism of ethylene elimination from diosmacyclobutanes, and (3) evidence for a ring-opening preequilibrium in ethylene dissociation from a diosmacyclobutane.

Goal: (long-term) understanding the factors that determine stereochemistry during metallacycle formation and cleavage; (immediate) explaining why the loss of olefins from $\left(\mu\right.$-olefin) $\mathrm{Os}_{2}(\mathrm{CO})_{8}$ is stereospecific when that from the analogous cyclobutane is not.

An example of olefin exchange by a diosmacyclobutane is shown below.

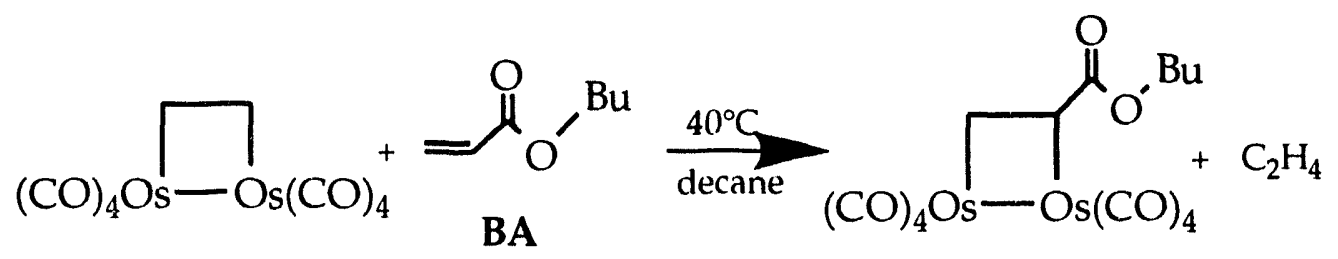

Any proposed mechanism must explain the high stereospecificity observed in these reactions ${ }^{6}$ in contrast to the complete loss of stereochemistry in the fragmentation of the isolobal cyclobutane. ${ }^{7}$ This complete loss of stereochemistry is attributable to the intermediacy of a tetramethylene diradical (eq 2). ${ }^{7}$ The possibility that an analogous diradical, such as depicted in eq 3 is involved in the exchange reactions of diosmacyclobutanes has been addressed in an earlier publication by this

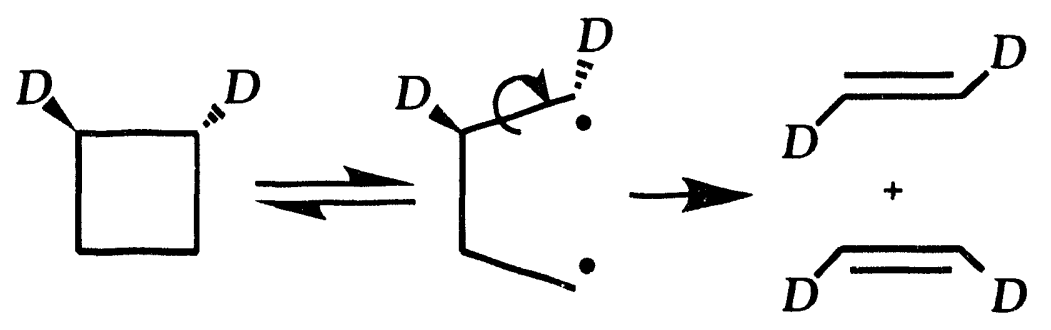




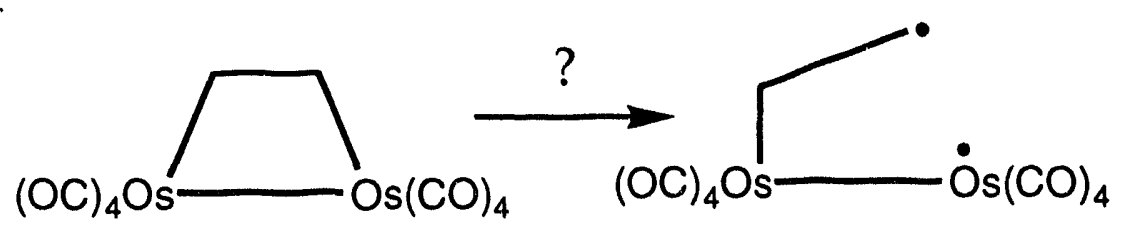

group 6 and by experiments reported in publication $\mathrm{c}$ - one of which is new.

Cyclopropyl substituents $\alpha$ to a radical have been shown to ring open with rate constants on the order of $10^{7} \mathrm{~s}^{-1} .8$ The introduction of such a substituent into a diosmacyclobutane should lead to products lacking intact cyclopropane substituents if the reaction proceeds through a diradical intermediate with a lifetime of $>10^{-6} \mathrm{~s}$. We have found that a large excess of vinyl cyclopropane cleanly displaces propene from $\mathrm{Os}_{2}(\mathrm{CO})_{8}\left(1,2-\right.$ di- $\sigma$-propene) (eq 4). The only species observable by ${ }^{1} \mathrm{H} \mathrm{NMR}$

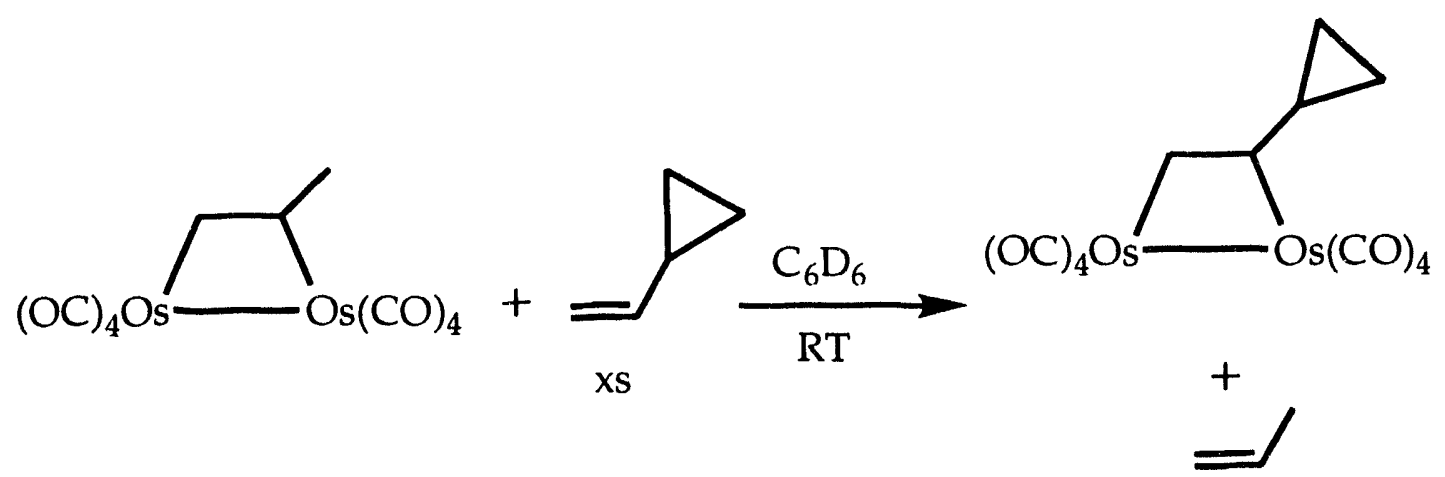

spectroscopy are the free olefins and $\mathrm{Os}_{2}(\mathrm{CO})_{8}(1,2-$ di- $\sigma$-vinyl cyclopropane $)$ - so reaction 1 definitely does not occur by a diradical mechanism.

Four possible mechanisms are shown on the following page. We have ruled out mechanism IV (simple associative) in view of the observation of saturation behavior as [BA] is increased. Mechanism I (simple dissociative) is an apparent violation of the symmetry rules for cycloadditions. Mechanisms II and III involve a "ring-opened" species 1 that we (publication a above) and others ${ }^{9}$ have seen in matrix isolation and transient IR experiments. As olefins coordinated to a single metal are known to exchange stereospecifically, the involvement of $\mathbf{1}$ offers an attractive explanation of the stereospecificity of these exchange reactions.

Mechanisms analogous to II and III have been proposed by Anslyn and Grubbs ${ }^{10}$ for titanacyclobutane cleavage; $\mathbf{1}$ is isolobal to the alkylidene olefin complexes they propose as intermediates.

Some evidence in favor of the intermediacy of $\mathbf{1}$ is offered by looking at exchange rates as a function of the departing olefin. The propene adduct of $\mathrm{Os}_{2}(\mathrm{CO})_{8}$ undergoes exchange more rapidly than the trans-2-butene adduct! This observation is contrary to the normal rules of olefin complex stability ${ }^{11}$ 


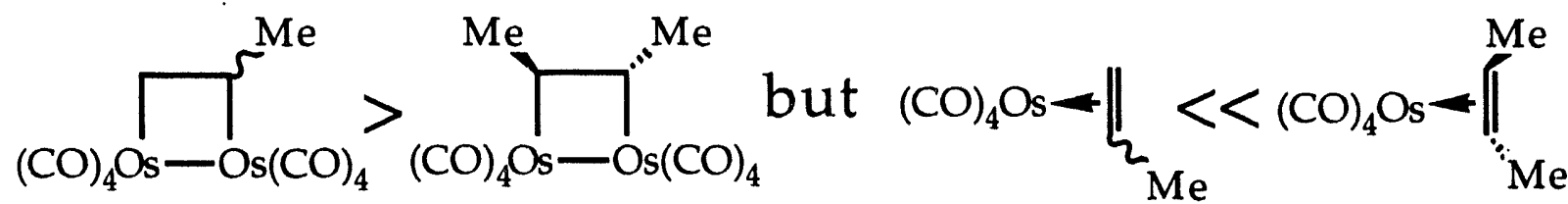

as exemplified by the mononuclear Os olefin complexes shown above. We have confirmed that the olefin dissociation rate constant $\mathrm{k}_{5}$ is much faster for $\mathrm{Os}(\mathrm{CO})_{4}$ (trans-2-butene) than for $\mathrm{Os}(\mathrm{CO})_{4}$ (propene). (We observe the saturation behavior expected for the mechanism shown - a mechanism analogous to that established for the analogous tetracarbonyl iron olefin system.12)

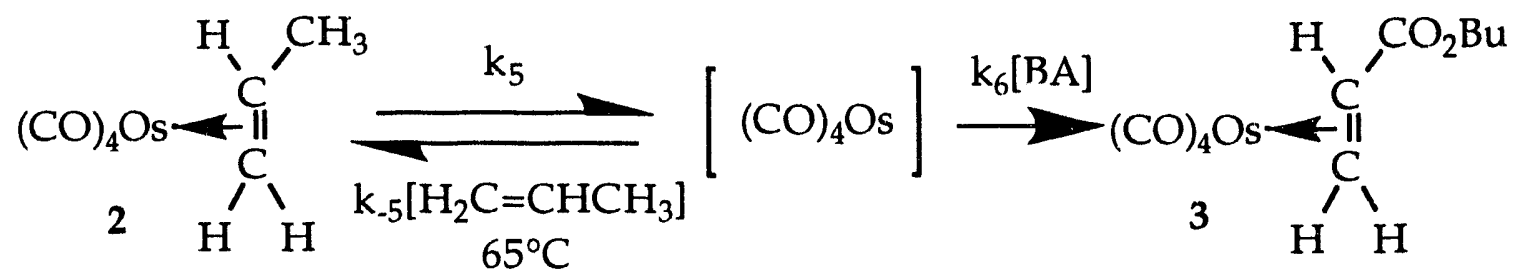

We attribute the anomalous stability of the $\mathrm{Os}_{2}(\mathrm{CO})_{8}($ trans-2-butene) adduct to unfavorable steric interactions in the ring-opened intermediate 1 . This is consistent with the results of molecular modeling studies performed in collaboration with Professor Anthony K. Rappé at CSU. Those studies indicate that the trans-2-butene version of 1 is destabilized at least $3 \mathrm{kcal} / \mathrm{mol}$ relative to its ethylene and propene analogs, due to close contact between the interior methyl group and a carbonyl on the adjacent Os atom (see page 7). This destabilization leads to relatively lower concentrations of the intermediate 1 , and lower overall rates of exchange, in the trans-2-butene case. 
Mechanism I

$(\mathrm{CO})_{4} \mathrm{Os}-\mathrm{Os}(\mathrm{CO})_{4} \underset{\mathrm{k}_{-1}\left[\mathrm{C}_{2} \mathrm{H}_{4}\right]}{\stackrel{\mathrm{k}_{1}}{=}}(\mathrm{CO})_{4} \mathrm{Os}=\mathrm{Os}(\mathrm{CO})_{4} \stackrel{\mathrm{k}_{2}[\mathrm{BA}]}{\longrightarrow}(\mathrm{CO})_{4} \mathrm{Os}-\mathrm{Os}(\mathrm{CO})_{4}$ $\frac{1}{k_{o b s}}=\left[\frac{k_{-1}}{k_{1} k_{2}}\left[\mathrm{C}_{2} \mathrm{H}_{4}\right]\right] \frac{1}{[\mathrm{BA}]}+\frac{1}{k_{1}}$

\section{Mechanism II}

$\prod_{(\mathrm{CO})_{4} \mathrm{Os}-\mathrm{Os}(\mathrm{CO})_{4} \underset{\mathrm{k}_{-1}}{\stackrel{k_{1}}{\rightleftharpoons}}(\mathrm{CO})_{4} \mathrm{Os}}$
$\frac{1}{k_{o b s}}=\left[\frac{k_{-1} k_{-2}}{k_{1} k_{2} k_{3}}\left[\mathrm{C}_{2} \mathrm{H}_{4}\right]+\frac{k_{-1}}{k_{1} k_{2}}\right] \frac{1}{[\mathrm{BA}]}+\frac{1}{k_{1}}$

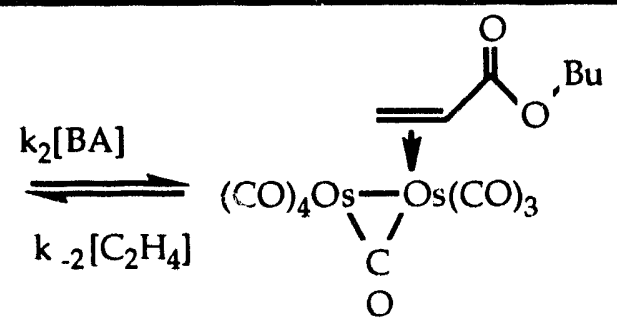

$(\mathrm{CO})_{4} \mathrm{Os}-\mathrm{Os}(\mathrm{CO})_{4}$

\section{Mechanism III}

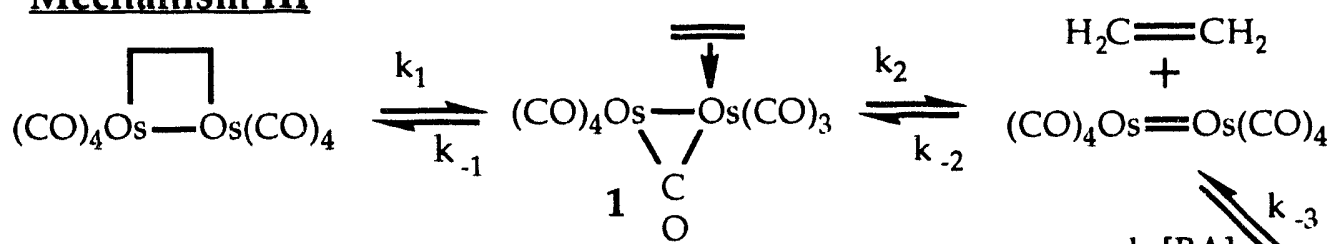

$\frac{1}{k_{\text {obs }}}=\left[\frac{k_{-1} k_{-2}\left(k_{-3}+k_{4}\right)}{k_{1} k_{2} k_{3} k_{4}}\left[\mathrm{C}_{2} \mathrm{H}_{4}\right]\right] \frac{1}{[\mathrm{BA}]}+\frac{k_{-1}+k_{2}}{k_{1} k_{2}}$

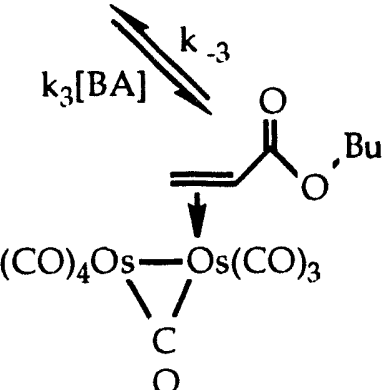

Mechanism IV

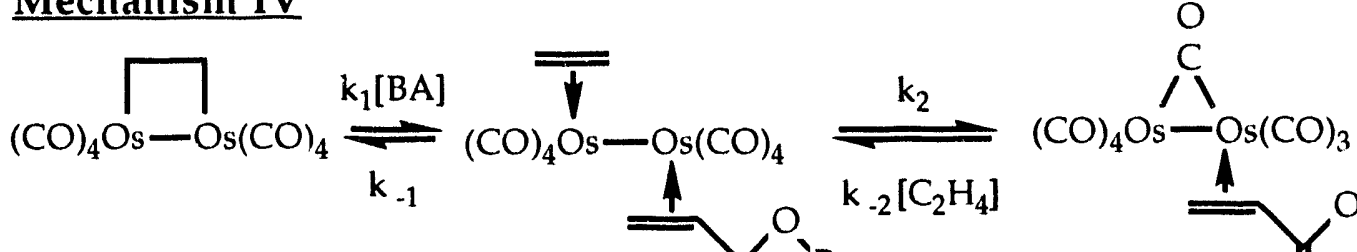
$(\mathrm{CO})_{4} \mathrm{Os}-\mathrm{Os}(\mathrm{CO})_{4} \quad$ C

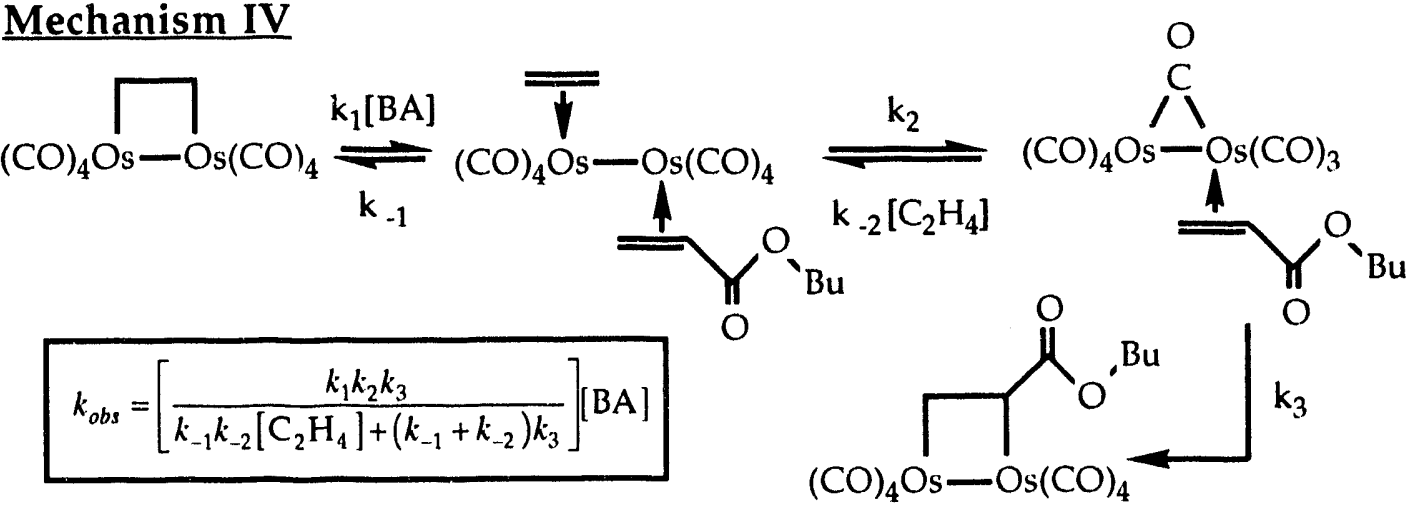




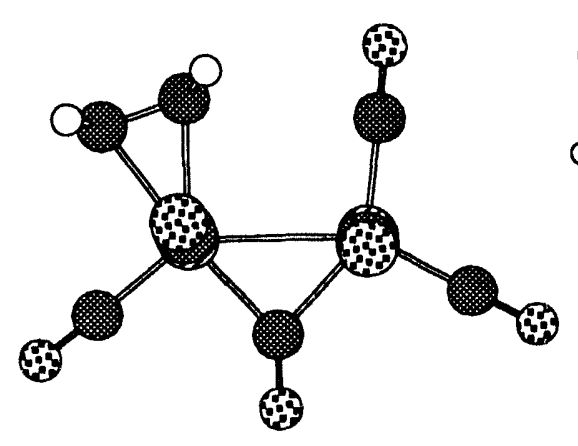

1-ethylene

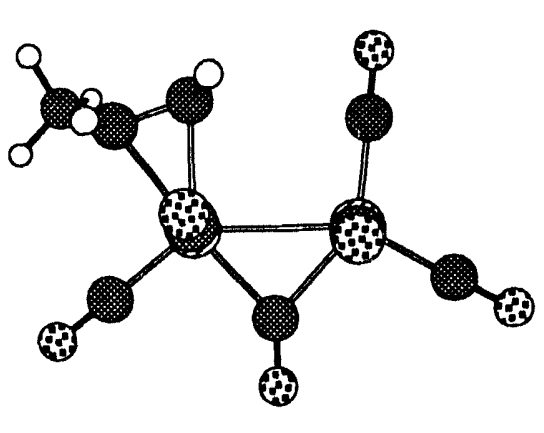

1-propene

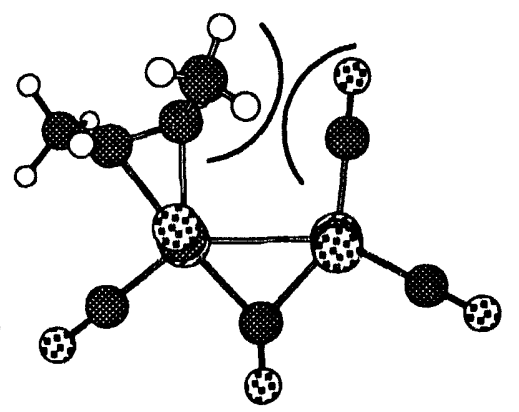

1-trans-2-butene

We have found that diosmacyclobutane exchange reactions like (1) proceed by the ring-opening/associative exchange mechanism: mechanism II. Both mechanisms II and III predict that a plot of $1 / \mathrm{k}_{o b s} v s$. [BA] at constant $\left[\mathrm{C}_{2} \mathrm{H}_{4}\right]$ should yield a straight line, the slope of which should show positive $\left[\mathrm{C}_{2} \mathrm{H}_{4}\right]$ dependence. Such slopes must be related to $\left[\mathrm{C}_{2} \mathrm{H}_{4}\right]$ by one of the following equations, if mechanism II or III is operative. Thus, if the slope from a $1 / \mathrm{k}_{\text {obs }}$ vs. [BA] plot is plotted $v s$. $\left[\mathrm{C}_{2} \mathrm{H}_{4}\right]$, a nonzero intercept should be obtained if mechanism II is the operative mechanism and a zero intercept otherwise.

\section{Mechanism II}

$$
\text { slope }=\left[\frac{k_{-1} k_{-2}}{k_{1} k_{2} k_{3}}\right]\left[\mathrm{C}_{2} \mathrm{H}_{4}\right]+\frac{k_{-1}}{k_{1} k_{2}}
$$

\section{Mechanism III}

$$
\text { slope }=\left[\frac{k_{-1} k_{-2}\left(k_{-3}+k_{4}\right)}{k_{1} k_{2} k_{3} k_{4}}\right]\left[\mathrm{C}_{2} \mathrm{H}_{4}\right]
$$

We have obtained slopes from numerous $1 / \mathrm{k}_{\mathrm{obs}}$ vs. [BA] plots and plotted these slopes vs. $\left[\mathrm{C}_{2} \mathrm{H}_{4}\right]$. Unfortunately, the solubility of $\mathrm{C}_{2} \mathrm{H}_{4}$ proved to vary as a function of $[\mathrm{BA}]$ and the simple graphical method described above did not give a solution. In collaboration with Professor James P. Kohn of the Chemical Engineering department at Notre Dame University we experimentally measured the solubility of $\mathrm{C}_{2} \mathrm{H}_{4}$ as a function of [BA] and were then able to calculate the actual $\left[\mathrm{C}_{2} \mathrm{H}_{4}\right]$ for each of our kinetic experiments. Multiple regression of the kinetic data implicated mechanism II.

The mononuclear substitution reaction in eq 5 shows a complication that provides insight into the mechanism of this reaction. At lower concentrations of BA the diosmacyclobutane $\mathrm{Os}_{2}(\mathrm{CO})_{8}\left(\mu-\eta, \eta^{\prime}-\mathrm{H}_{2} \mathrm{C}=\mathrm{CHCO}_{2} \mathrm{Bu}\right)$ is observed as a coproduct from the mononuclear olefin exchange reaction. No induction period is observed in the formation of this binuclear product, and the 3/4 ratio decreases with decreasing BA concentration. These results suggest the following mechanism of formation. The resulting rate law, written in terms of disappearance of the starting material 1, correctly predicts the behavior of the system as [BA] is varied. The observation that significant amounts of 4 are formed at low [BA] provides compelling evidence (in addition to the saturation kinetics already noted at high [BA]) for the intermediacy of $\mathrm{Os}(\mathrm{CO})_{4}$ in eq 6. 


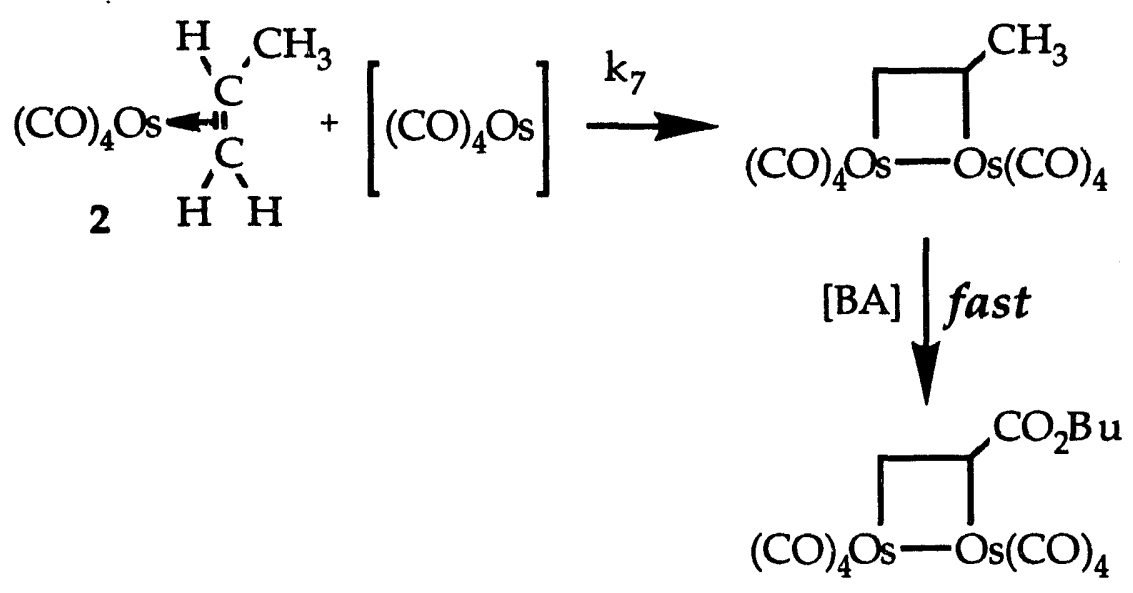

$$
-\frac{\mathrm{d}[2]}{\mathrm{dt}}=\frac{k_{5} k_{6}[2][\mathrm{BA}]+k_{5} k_{7}[2]^{2}}{k_{-5}\left[\mathrm{H}_{2} \mathrm{C}=\mathrm{CHCH}_{3}\right]+k_{6}[\mathrm{BA}]+k_{7}[2]}
$$

\section{Reaction of dienes and allenes with diosmacyclobutanes}

\section{Publications:}

"The Reaction of 1,3-Butadiene and Allene with a Diosmacyclobutane", N. Spetseris and J. R. Norton; written, about to be submitted.

Question to be Answered: Do dienes add 1,2 or 1,4 to $\mathrm{Os}_{2}(\mathrm{CO})_{8}$ ?

Our conclusion in the preceding section (that Mechanism II is correct) implies that the exchange reactions of diosmacyclobutanes do not involve free $(\mathrm{CO})_{4} \mathrm{Os}=\mathrm{Os}(\mathrm{CO})_{4}$. However, before that result had been established we decided to investigate whether these reactions gave 1,4 or 1,2 addition products when the $(\mathrm{CO})_{4} \mathrm{Os}=\mathrm{Os}(\mathrm{CO})_{4}$ unit was transferred to a diene. The former $(1,4$ addition) is of course observed when a carbon-carbon double bond reacts with a diene, and would be expected with free $(\mathrm{CO})_{4} \mathrm{Os}=\mathrm{Os}(\mathrm{CO})_{4}$ (Scheme I). 


\section{Scheme I}

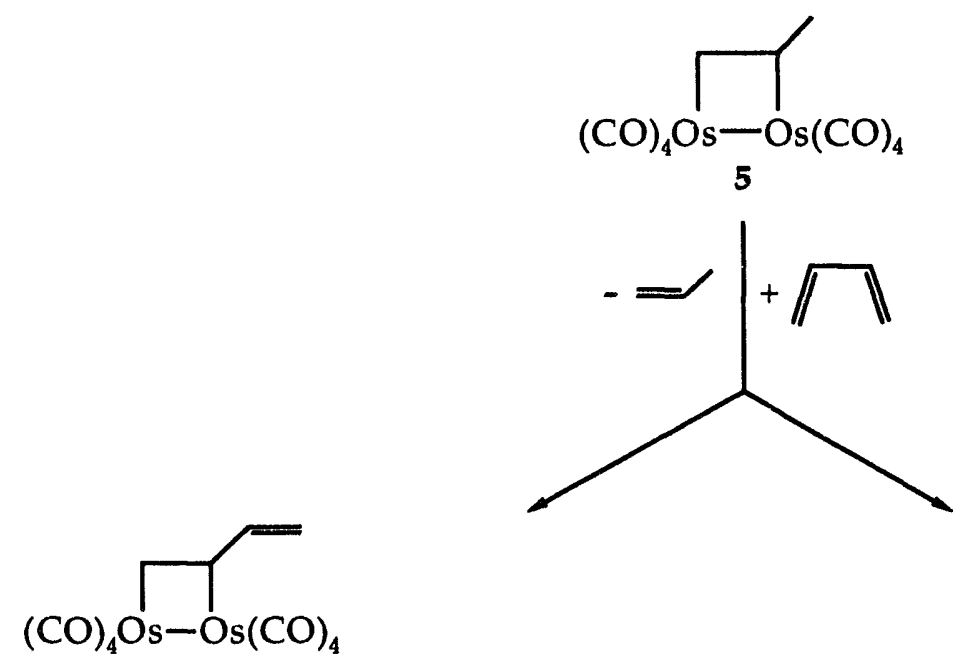

(1, 2-addition product)

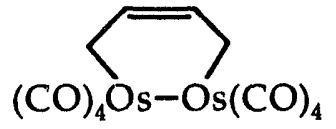

(1, 4-addition product)

Instead, the reaction between the diosmacyclobutane 5 and butadiene (eq 7) gave the 1,2 addition product 6 as well as compound 7. The kinetic product 6 rearranges to 7 , with an equilibrium constant of 8.9 .

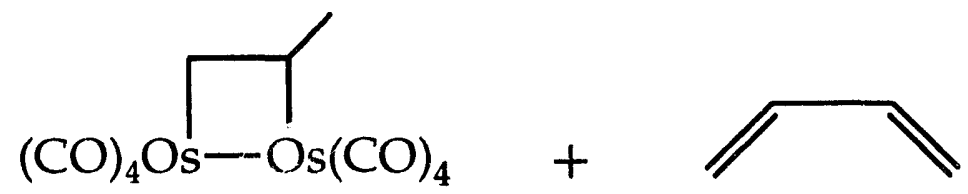

5

$$
11
$$<smiles>C=CC1CS(=O)(=O)OC1(C)C(=O)O</smiles>

6

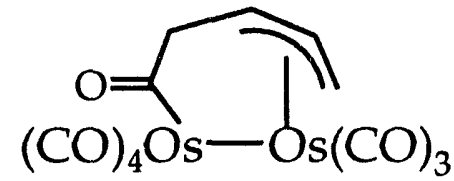

7

The reaction of $\left[\mathrm{Os}_{2}(\mathrm{CO})_{8}\right]^{2-}$ with either cis- or trans- $\mathrm{ClCH}_{2} \mathrm{CH}=\mathrm{CHCH}_{2} \mathrm{Cl}$, or with $\mathrm{CH}_{2}=\mathrm{CHCHClCH} 2 \mathrm{Cl}$, gives compound 8. Photolysis of $\mathrm{Os}_{3}(\mathrm{CO})_{12}$ in the presence of butadiene gives the dinuclear compounds 7 and 8 as well as $\mathrm{Os}(\mathrm{CO})_{3}$ (butadiene). 


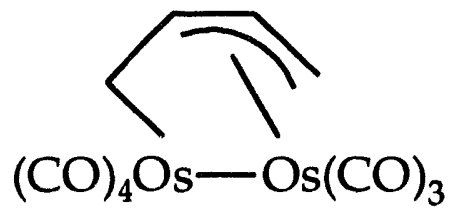

8

The sructure of 8 has been confirmed by x-ray crystallography. An ORTEP is shown below.

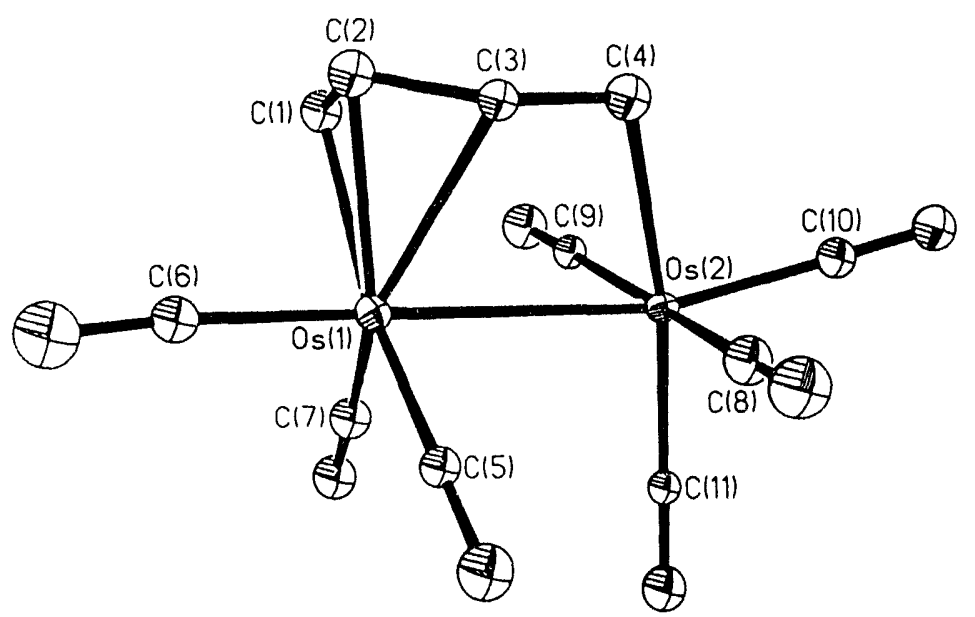

The transfer of the $(\mathrm{CO})_{4} \mathrm{Os}=\mathrm{Os}(\mathrm{CO})_{4}$ unit to allene also occurs by 1,2 addition (eq 8).

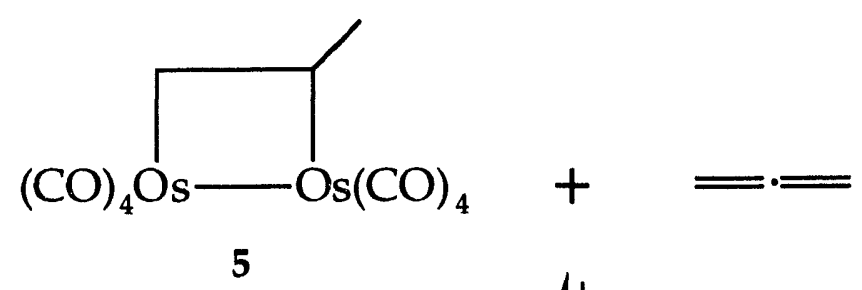<smiles>CC(=O)O[R5](C)(C)C</smiles>

9

$\|$

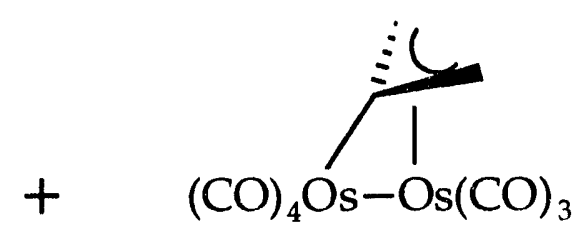

10

Comparison of reaction $5(5+$ allene) with reaction $4(5+$ butadiene $)$ shows that the transfer of a " $(\mathrm{CO})_{4} \mathrm{Os}=\mathrm{Os}(\mathrm{CO})_{4}$ " unit to allene is more favorable than to 
butadiene. The equilibrium constant for reaction 5 (displacement of propylene from 5 by allene) is 53.1, whereas that for reaction 4 (displacement of propylene from 5 by butadiene) is only 10.9. However, the heat of hydrogenation of one double bond of allene exceeds that of butadiene by $14.2 \mathrm{kcal} \mathrm{mol}^{-1}, 13$ predicting a much larger difference in equilbrium constants than is observed between eqs 7 and 8; there is probably significant strain in the diosmacyclobutane ring of 9.

Compound 9, the kinetic product of reaction 5, rearranges to the more thermodynamically stable and previously reported 14 10. (The 1,2 addition product 9 represents a new bonding mode for allene as a bridging ligand in dinuclear centers. ${ }^{15}$ ) Photolysis of $\mathrm{Os}_{3}(\mathrm{CO})_{12}$ in the presence of allene gives $\mathrm{Os}(\mathrm{CO})_{4}$ (allene) and 10 (eq 9).

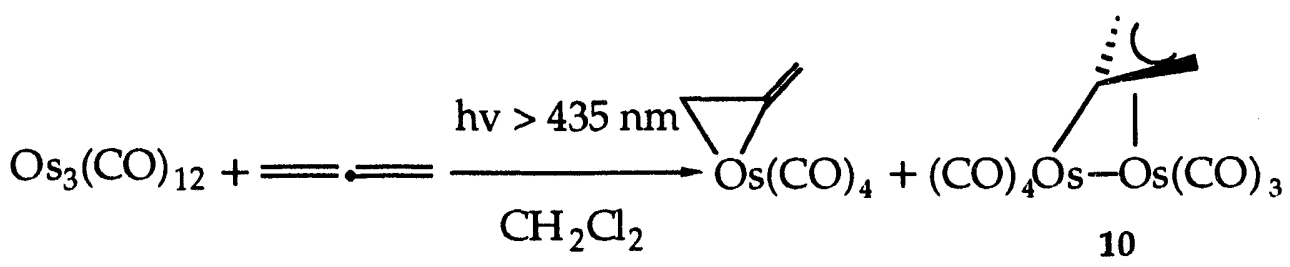

The observation of 1,2 addition products in both of the above cases is consistent with, and indeed predicted by, the mechanism established in Section C.

E. "The Structure of $\mathrm{Os}(\mathrm{CO})_{4}\left(\mathrm{C}_{2} \mathrm{H}_{4}\right)$, an Osmacyclopropane", B.R. Bender, J.R. Norton*, M.M. Miller, O.P. Anderson, and A.K. Rappé*, Organometallics 1992, 11, 3427-3434.

A nearly complete draft of another publication - describing the structure of $\mathrm{Os}(\mathrm{CO})_{4}\left(\mathrm{C}_{2} \mathrm{H}_{4}\right)$ in a nematic phase solvent - was written almost a year ago. It lacks only the appropriate vibrational corrections, which require the normal mode data that our collaborators at East Anglia (Anson and Sheppard) have promised but not yet delivered.

Question to be Answered: how much osmacyclopropane character does $\mathrm{Os}(\mathrm{CO})_{4}\left(\mathrm{C}_{2} \mathrm{H}_{4}\right)$ possess? Goal: synthesis of coordinatively unsaturated alkyl carbonyl cations

The value of ${ }^{1} J_{13} \mathrm{C}-13 \mathrm{C}$ for an ethylene coordinated to $\mathrm{Os}(\mathrm{CO})_{4}$ has been determined from the ${ }^{1} \mathrm{H}$ NMR spectrum of $\mathrm{Os}(\mathrm{CO})_{4}\left(\eta^{2}-13 \mathrm{C}_{2} \mathrm{H}_{4}\right)$. X-ray analysis shows the geometry of $\mathrm{Os}(\mathrm{CO})_{4}\left(\eta^{2}-\mathrm{C}_{2} \mathrm{H}_{4}\right)(\mathbf{1 1})$ to be approximately trigonal bipyramidal, with the ethylene carbons twisted out of the equatorial plane by $4.0^{\circ}$. The axial carbonyls of $\mathbf{1 1}$ tilt toward the coordinated ethylene, with a C1-Os-C1' angle of $171.3(5)^{\circ}$. The optimal geometries of $\mathrm{Os}(\mathrm{CO})_{4}, \mathrm{H}_{2} \mathrm{Os}(\mathrm{CO})_{4}$, and 11 have been calculated by Hartree Fock methods. The orbital amplitude contour diagrams of a $\mathrm{GVB}(6 / 12)$ wavefunction for $\mathbf{1 1}$ show that the axial bending occurs in order to mix in virtual $p_{\pi}$ character and improve backbonding to the equatorial carbonyls; they also show that $\mathbf{1 1}$ is best described as a metallacyclopropane. 
One would thus expect the kinetic site of electrophilic attack on 11 to be carbon, despite the strength of the Os-H bond. We have therefore begun to examine the protonation of $\mathbf{1 1}$ by acids with weakly coordinating anions. (The potential uses of the cations thereby generated will be discussed in "Plans for Future Research".)

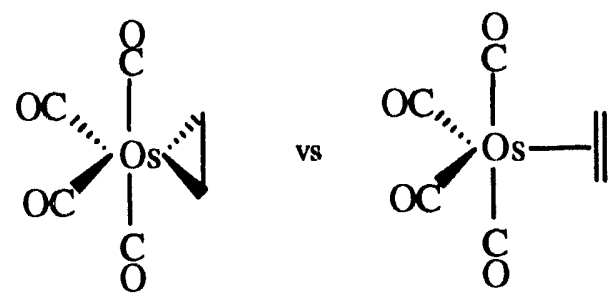

Use of $\mathrm{HBF}_{4} \cdot \mathrm{Me}_{2} \mathrm{O}$ in $\mathrm{CH}_{2} \mathrm{Cl}_{2}$ gives the insoluble 12 with $\eta^{1}-\mathrm{BF}_{4}^{-}$; the $\mathrm{BF}_{4}^{-}$is displaced by coordinating solvents such as acetone to give 13 Use of $\mathrm{CF}_{3} \mathrm{SO}_{3} \mathrm{H}$ gives the soluble 14. We have seen no evidence for Os-H bond formation, or even for an agostic interaction between the $\mathrm{Os}$ and a $\mathrm{C}-\mathrm{H}$ bond.

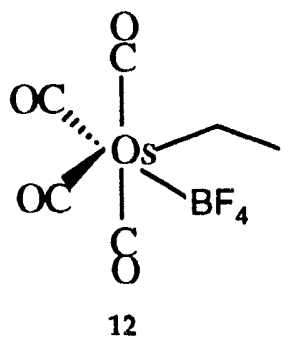

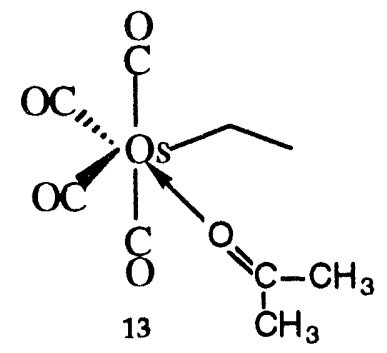<smiles></smiles>

Use of the Bookhart acid $\left[\mathrm{H}^{+}\left(\mathrm{Et}_{2} \mathrm{O}\right)_{2} \mathrm{BAr}_{4}{ }^{-}\right]^{16}$ has allowed us to establish that the osmium is the initial site of protonation of 11, with the kinetic products 15 and 16 rearranging over several hours at $0^{\circ} \mathrm{C}$ to the thermodynamic product 17.

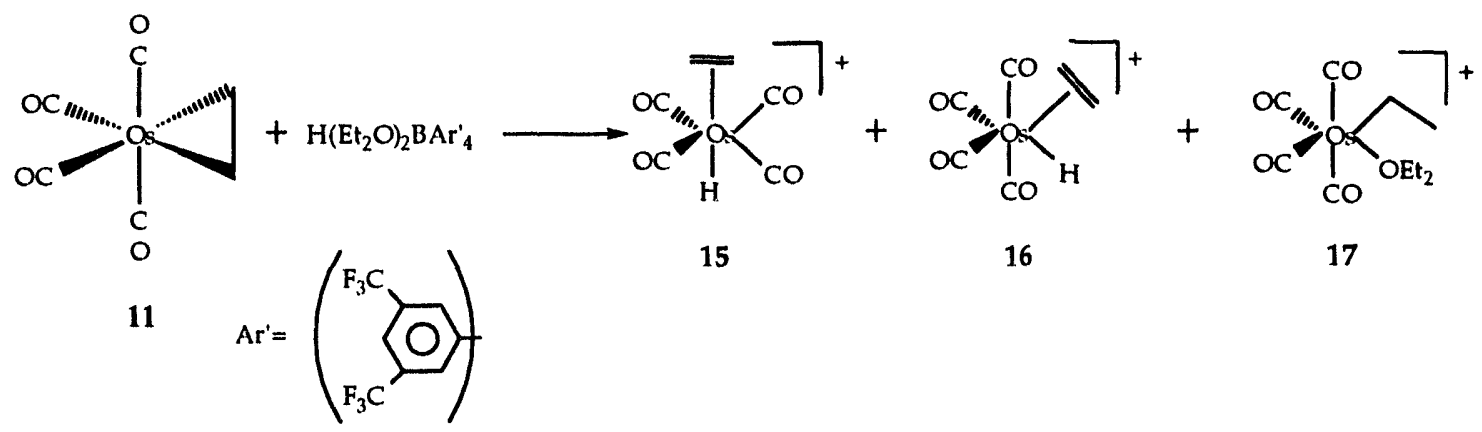

Like CpRe(CO) $)_{2}$ (alkene) complexes, ${ }^{17} \mathrm{Os}(\mathrm{CO})_{4}$ complexes of substituted olefins give cationic allyl complexes when treated with $\mathrm{Ph}_{3} \mathrm{C}^{+}$. For example, $\mathrm{Os}(\mathrm{CO})_{4}\left(\mathrm{CH}_{3} \mathrm{CH}=\mathrm{CH}_{2}\right)$ gives $\left[\mathrm{Os}(\mathrm{CO})_{4}\left(\mathrm{CH}_{2} \mathrm{CHCH}_{2}\right)\right]^{+}$, and $\mathrm{Os}(\mathrm{CO})_{4}\left(\mathrm{CH}_{3} \mathrm{CH}_{2} \mathrm{CH}=\mathrm{CH}_{2}\right)$ gives $\left[\mathrm{Os}(\mathrm{CO})_{4}\left(\mathrm{CH}_{3} \mathrm{CHCHCH}_{2}\right)\right]^{+}$. 
F. "Reaction of $\mu$-Oxobis[(trifluoromethanesulfanato)(phenyl)iodine(III)] with Group 14 Propargyl Derivatives and a Propargyl Ether", D.A. Gately, T.A. Luther, J.R. Norton*, M.M. Miller, and O.P. Anderson, J. Org. Chem. 1992, 57, 6496-6502.

Question to be Answered: does [PhI(OTf) $]_{2} \mathrm{O}$ react with alkynes in any useful way? (We used the reaction of this reagent with olefins to generate the vicinal ditriflates required for the synthesis of diosmacyclobutanes.)

We have discovered a novel allenyl "Claisen" rearrangement while exploring the reactions of an I(III) reagent with triple bonds. 18 We have shown that the intramolecular H/D isotope effect is negligible, as previously reported ${ }^{19}$ for the Claisen rearrangement of 2-deuteriophenyl propargyl ether.

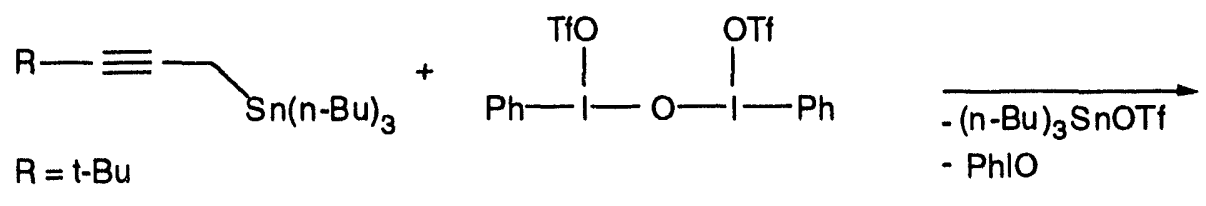<smiles>[R]C#CCC1C=CC=CC1=IO</smiles><smiles>[2H]C#CCc1ccccc1I</smiles><smiles></smiles>

proposed allenyliodinane

We have discovered that a side chain ether oxygen can control the regioselectivity with which the reagent adds to triple bonds. The reaction below gives only the product shown. 


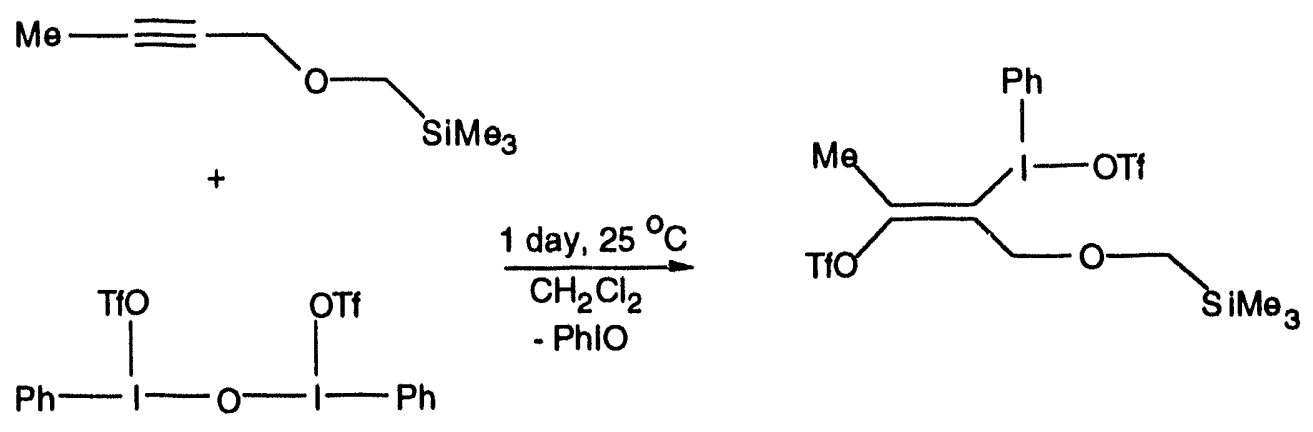




\section{REFERENCES}

1(a) Ibach, H.; Lehwald, W. J. Vac. Sci. Technol. 1978, 15, 407. (b) Kesmodel, L. L.; Dubois, L. H.; Somorjai, G. A. J. Chem. Phys. 1979, 70, 2180. (c) Skinner, P.; Howard, M. W.; Oxton, I. A.; Kettle, S. F. A.; Powell, D. B.; Shappard, N. J. Chem. Soc. Faraday Trans. 2 1981, 77, 1203. (d) Steininger, H.; Ibach, H.; Lehwald, S. Surf. Sci. 1982, 117, 685.

2Kroeker, R. M.; Kaska, W. C.; Hansma, P. K. J. Catal. 1980, 61, 87.

3 Stuve, E. M.; Madix, R. J. J. Phys. Chem. 1985, 89, 105.

4 Bent, B. E.; Mate, C. M.; Kao, C.-T.; Slavin, A. J.; Somorjai, G. A. J. Plyys. Chem., $1988,92,4720$.

5Lindner, E.; Jansen, R.-M.; Hiller, W.; Fawzi, R. Chem. Ber. 1989, 122, 1403.

6 Hembre, R. T.; Scott, C. P.; Norton, J. R. J. Am. Chem. Soc. 1987, 109, 3468-3470.

7(a) Chickos, J. S.; Annamalai, A.; Keiderling, T. A. J. Am. Chem. Soc. 1986, 108, 43984402. (b) Chikos, J. S. J. Org. Chem. 1979, 44, 780-784.

8 (a) Bowry, V. W.; Lusztyk, J.; Ingold, K. U. J. Am. Chem. Soc. 1991, 113, 5687. (b)

Newcomb, M. Tetrahedron, 1993, 49, 1151.

${ }^{9}$ Grevels, F.-W.; Klotzbücher, W. E.; Seils, F.; Schaffner, K.; Takats, J. J. Am. Chem. Soc. 1990, 112, 1995.

10(a) Anslyn, E. V.; Grubbs, R. H. J. Am. Chem. Soc. 1987, 109, 4880. (b) Finch, W. C.; Anslyn, E. V.; Grubbs, R. H. J. Am. Chem. Soc. 1988, 110, 2406. (c) Hawkins, J. M.; Grubbs, R. H. 1988, 110, 2821.

11(a) Hartley, F. R. Chem. Rev. 1969, 69, 799-844. (b) Henry, P. M. J. Am. Chem. Soc. 1966, 88, 1595-1597.

${ }^{12}$ Cardaci, G.; Narciso, V. J. J. Chem. Soc., Dalton Trans. 1972, 2289-2293.

13Jensen, J. L. Prog. Phys. Org. Chem. 1976, 12, 189.

14Deeming, A. J.; Arce, A. J.; De Sanctis, Y. J. Chem. Soc., Dalton Trans. 1987, 2935. 15 (a) Chacon, S. T.; Chisholm, M. H.; Folting, K.; Huffman, J. C.; Hampden-Smith, M. J. Organometallics 1991, 10, 3722. (b) Seyferth, D.; Anderson, L. L.; Davis, W. B.; Cowie, LM. Organometallics 1992, 11, 3736.

16 Brookhart, M.; Grant, B.; Volpe, A. F. Organometallics 1992, 11, 3920.

17Casey, C. P.; Yi, C. S. Organometallics 1990, 9, 2413.

18 Similar chemistry has been reported by Ochiai and co-workers: (a) Ochiai, M.; Ito, T.; Takaoka, Y.; Masaki, Y. J. Am. Chem. Soc. 1991, 113, 1319. (b) Ochiai, M.; Ito, T.; Masaki, Y. J. Chem. Soc., Chem. Commun. 1992, 15.

${ }^{19}$ Al-Sader, B. H.; Al-Fekri, D. M. J. Org. Chem. 1978, 43, 3627. 

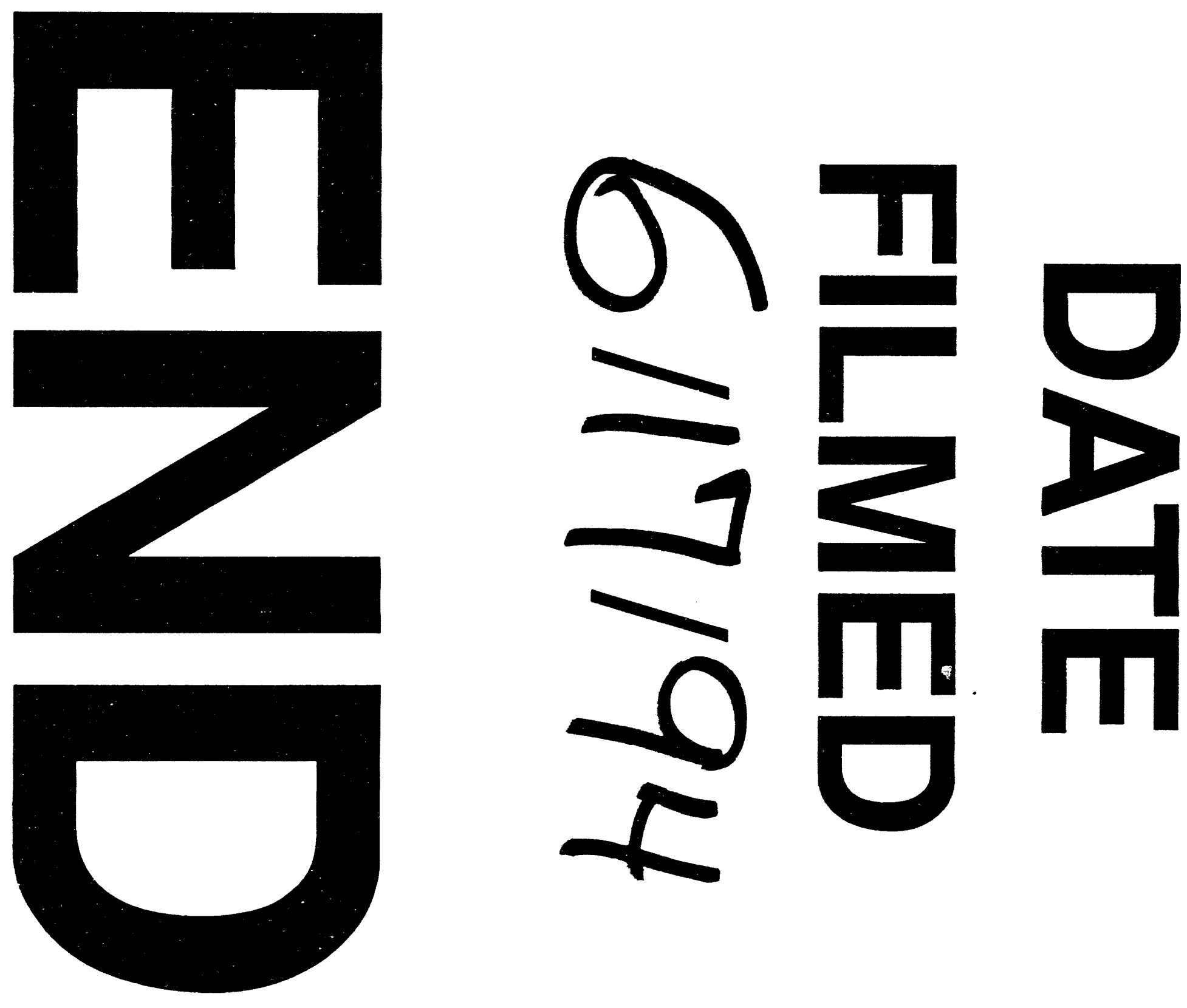
